\title{
Mitochondrial calcium: Transport and modulation of cellular processes in homeostasis and cancer (Review)
}

\author{
SUSANA ROMERO-GARCIA and HERIBERTO PRADO-GARCIA \\ Department of Chronic-Degenerative Diseases, National Institute of Respiratory Diseases \\ 'Ismael Cosío Villegas', CP 14080 Mexico City, Mexico
}

Received August 20,2018; Accepted December 6, 2018

DOI: 10.3892/ijo.2019.4696

\begin{abstract}
In addition to their role in providing cellular energy, mitochondria fulfill a key function in cellular calcium management. The present review provides an integrative view of cellular and mitochondrial calcium homeostasis, and discusses how calcium regulates mitochondrial dynamics and functionality, thus affecting various cellular processes. Calcium crosstalk exists in the domain created between the endoplasmic reticulum and mitochondria, which is known as the mitochondria-associated membrane (MAM), and controls cellular homeostasis. Calcium signaling participates in numerous biochemical and cellular processes, where calcium concentration, temporality and durability are part of a regulated, finely tuned interplay in non-transformed cells. In addition, cancer cells modify their MAMs, which consequently affects calcium homeostasis to support mesenchymal transformation, migration, invasiveness, metastasis and autophagy. Alterations in calcium homeostasis may also support resistance to apoptosis, which is a serious problem facing current chemotherapeutic treatments. Notably, mitochondrial dynamics are also affected by mitochondrial calcium concentration to promote cancer survival responses. Dysregulated levels of mitochondrial calcium, alongside other signals, promote mitoflash generation in tumor cells, and an increased frequency of mitoflashes may induce epithelial-to-mesenchymal transition. Therefore, cancer cells remodel their calcium balance through numerous mechanisms that support their survival and growth.
\end{abstract}

\section{Contents}

1. Introduction

2. Mitochondrial calcium homeostasis

Correspondence to: Dr Susana Romero-Garcia, Department of Chronic-Degenerative Diseases, National Institute of Respiratory Diseases 'Ismael Cosío Villegas', Tlalpan 4502, Col. Sección XVI, CP 14080 Mexico City, Mexico

E-mail: sugar_cia@yahoo.com

Key words: mitochondria-associated membrane, calcium transport, mitochondrial dynamics, mesenchymal transformation, cell migration, invasiveness, metastasis, autophagy, mitoflash
3. Mitochondrial calcium transport

4. Calcium interplay between ER and mitochondria shapes mitochondrial function and dynamics

5. Calcium signals control cell migration and apoptosis

6. Calcium interplay is remodeled by cancer: Alterations in MAM and mitochondrial dynamics

7. Mitochondrial calcium and mitoflashes in epithelial-tomesenchymal transformation

8. Calcium: a critical regulator of tumor migration, invasiveness and metastasis

9. Mitochondrial calcium in tumor apoptotic failure and tumor autophagy

10. Conclusions

\section{Introduction}

Calcium $\left(\mathrm{Ca}^{2+}\right)$ signaling regulates various physiological processes, including muscle contraction, neuron excitability, cellular secretion and cell migration $(1,2)$. At the cellular level, fine-tuned regulation of intracellular $\mathrm{Ca}^{2+}$ levels is essential for maintaining cell survival, cell function and mitochondrial dynamics, which are the focus of the first part of this review.

Total cellular $\mathrm{Ca}^{2+}$ levels are maintained through the sum of $\mathrm{Ca}^{2+}$ influx that occurs through the plasma membrane using cation channels and the release of $\mathrm{Ca}^{2+}$ from intracellular $\mathrm{Ca}^{2+}$ stores. The endoplasmic reticulum (ER) and mitochondria are the main $\mathrm{Ca}^{2+}$ stores. The role of mitochondria in calcium homeostasis is important because of its function as the main cellular chamber involved in ATP production, and because there is a link between mitochondrial levels of calcium and mitochondrial dynamics, function and metabolism. Mitochondria are also involved in cellular microdomains that regulate vital cellular processes $(3,4)$.

Cancer remodels the systems that maintain cellular calcium homeostasis, including $\mathrm{Ca}^{2+}$ transporters and their regulators, $\mathrm{Ca}^{2+}$-dependent enzyme activity and accessory molecules that will support tumor development. These processes are discussed in the second part of the present review.

\section{Mitochondrial calcium homeostasis}

Mitochondrial calcium homeostasis is regulated through a fine-tuned process that defines the capacity of the mitochondria 
for handling calcium. This process is critical for the regulation of aerobic metabolism and cell survival (5). In this manner, mitochondria an important role in modulating the amplitude and timing of intracellular $\mathrm{Ca}^{2+}$ signals through two mechanisms (6): Mitochondrial calcium buffering capacity and mitochondrial functional interactions with other channels or organelles.

Mitochondria possess a calcium buffering capacity that can handle levels of intracellular calcium between 50 and $500 \mathrm{nM}$ in numerous types of normal cells (7-9). Through this buffering activity, mitochondria may dynamically manage transient alterations in calcium concentrations and may buffer severe $\mathrm{Ca}^{2+}$ overloads, which are often associated with pathological conditions (9). Notably, mitochondria can functionally interact with calcium-channel gating in the cell membrane of $\mathrm{T}$ lymphocytes. A prolonged elevation of cytosolic $\mathrm{Ca}^{2+}$ is required for T-cell activation, and functional mitochondria prevent a local accumulation of $\mathrm{Ca}^{2+}$ near sites that govern channel activation and maintain an opened $\mathrm{Ca}^{2+}$ release-activated $\mathrm{Ca}^{2+}$ (CRAC)-channel (10).

The close contact between mitochondria and cellular $\mathrm{Ca}^{2+}$ gates present in the ER and the cell membrane creates microdomains that allow the increase of mitochondrial calcium concentration $\left(\left[\mathrm{Ca}^{2+}\right]_{\mathrm{m}}\right)$ in parallel to cytosolic $\mathrm{Ca}^{2+}$ signals, despite the low affinity of $\left[\mathrm{Ca}^{2+}\right]_{\mathrm{m}}$ uptake systems (11). Numerous close contacts have been observed between mitochondria and the ER, where, upon opening of the inositol 1,4,5-triphosphate $\left(\mathrm{IP}_{3}\right)$-gated channels in the ER, the surface of the mitochondria is exposed to higher concentrations of $\mathrm{Ca}^{2+}$ than the bulk cytosol, which increases $\left[\mathrm{Ca}^{2+}\right]_{\mathrm{m}}$ (Fig. 1) $(12,13)$. In addition, microdomains between the mitochondria and cell membrane allow the entrance of extracellular calcium through cell membrane channels to the mitochondria, providing a link between cellular activation and mitochondrial function (Fig. 1) (9). The rapid diffusion of intracellular $\mathrm{Ca}^{2+}$ avoids organelle overload (12).

\section{Mitochondrial calcium transport}

Calcium can be transported into the mitochondria using voltage-dependent anion channels (VDACs) that exist on the outer mitochondrial membrane (OMM) in excitable cells, including neurons, muscle cells and fibroblasts. VDACs can form a large conductance channel in lipid bilayers (14). Furthermore, VDACs exist in the cell membrane of neurons and retinal amacrine cell $(15,16)$. VDACs can also transport other small molecules and ions; $\mathrm{Ca}^{2+}$ can regulate VDAC activity, thus controlling permeability to ions and small molecules through the OMM. Elevations of $\left[\mathrm{Ca}^{2+}\right]$ to the micromolar range induce higher conductance and sustain VDAC opening. Notably, $\left[\mathrm{Ca}^{2+}\right]_{\mathrm{m}}$ uptake is often driven by spikes and oscillations in $\left[\mathrm{Ca}^{2+}\right]$, which are characterized by short-lasting events; under physiological ionic conditions VDACs often present closed conformations (Fig. 1) (14).

Calcium is transported by the mitochondrial calcium uniporter (MCU), a ruthenium-red-sensitive uniporter that utilizes the negative potential across the inner mitochondrial membrane (IMM) (17). MCU pentamerizes in the IMM as part of a larger molecular weight complex; the other subunits are mitochondrial calcium uptake 1 and 2 (MICU1 and MICU2), and the essential MCU regulator (EMRE). MICU1 and MICU2 serve as calcium sensors that allow $\mathrm{Ca}^{2+}$-dependent opening of the MCU pore. EMRE is a single-pass membrane protein required to allow $\mathrm{Ca}^{2+}$ access (Fig. 1). When $\mathrm{Ca}^{2+}$ concentration around the MCU is $>1 \mathrm{mM}$, the channel opens and allows $\mathrm{Ca}^{2+}$ to enter into the matrix that is driven by the large negative membrane potential of the IMM (18). In endothelial cells exposed to various glucose concentrations (2-30 mM), MCU and MICU1 are upregulated in a dose- and time-dependent manner. Therefore, endothelial cells under hyperglycemic stress exhibit cell dysfunction associated with $\left[\mathrm{Ca}^{2+}\right]_{\mathrm{m}}$ overload, which results in an increase in reactive oxygen species (ROS) that promotes apoptosis (19).

The primary mechanism underlying calcium extrusion in excitable cells is the $\mathrm{Na}^{+} / \mathrm{Ca}^{2+} / \mathrm{Li}^{+}$exchanger (NCLX); this transporter exchanges mitochondrial matrix calcium for external sodium or lithium, hence its name $(20,21)$. Therefore, to allow activity of the $\mathrm{Na}^{+} / \mathrm{Ca}^{2+}$ antiporter, matrix $\mathrm{Na}^{+}$must be exchanged for external $\mathrm{H}^{+}$by $\mathrm{a} \mathrm{Na}^{+} / \mathrm{H}^{+}$exchanger(22). In addition, $\mathrm{Ca}^{2+}$ efflux might occur via a $\mathrm{Ca}^{2+} / \mathrm{H}^{+}$exchanger, which is expressed in acidic organelles, including mitochondria $(22,23)$. The mitochondrial $\mathrm{K}^{+} / \mathrm{H}^{+}$exchanger (KHE) also participates in mitochondrial calcium dynamics; however, KHE discriminates poorly between $\mathrm{K}^{+}$and other monovalent cations, extruding $\mathrm{Na}^{+}$ by $\mathrm{H}^{+}$. Another IMM protein that has $\mathrm{K}^{+} / \mathrm{H}^{+}$exchange activity is the leucine zipper-EF-hand containing transmembrane protein 1 (LETM1). Lowering LETM1 expression via short hairpin RNA hampers mitochondrial $\mathrm{K}^{+}$or $\mathrm{Na}^{+} / \mathrm{H}^{+}$exchange. Furthermore, LETM1 downregulation decreases $\mathrm{Na}^{+} / \mathrm{Ca}^{2+}$ exchange mediated by the NCLX (22). Furthermore, LETM1 is able to transport $\mathrm{Ca}^{2+}$ in a $\mathrm{pH}$-dependent manner. When the $\mathrm{pH}$ shifts from acidic to alkaline, LETM1 opens a central cavity allowing $\mathrm{Ca}^{2+} / \mathrm{H}^{+}$antiporter (24). Therefore, a fine-tuning interplay exists among $\left[\mathrm{Ca}^{2+}\right],\left[\mathrm{Na}^{+}\right],\left[\mathrm{Li}^{+}\right],\left[\mathrm{K}^{+}\right]$and $\left[\mathrm{H}^{+}\right]$at the mitochondrial matrix and in the intermembrane space where calcium is a key player (Fig. 1).

\section{Calcium interplay between ER and mitochondria shapes mitochondrial function and dynamics}

Mitochondria associated membrane (MAM) is a key microdomain in calcium homeostasis. At the cellular level, calcium has a role in how mitochondria interact with other organelles, including the ER, which can also affect mitochondrial function and dynamics. The spatially restricted domain created between the ER and the mitochondria is known as the MAM. Notably, 20\% of the mitochondria surface is in close contact with the ER, where the ER protein vesicle-associated membrane protein associated protein B (VAPB) is the scaffold that tethers the ER to the mitochondrial protein, protein tyrosine phosphatase interacting protein 51 (Fig. 1) (13). Another molecule that participates in tethering the ER and mitochondria together is mitofusin 2 (MFN2), which also has GTPase activity (25), wherein B-cell lymphoma-2 (Bcl-2) related protein ovarian killer increases MFN2 to cause tethering of the ER and mitochondria to facilitate mitochondrial fission (26). Additionally, MAM functions as a critical membrane contact site for lipid synthesis and exchange (26). The importance of MAM communication is underlined in various human diseases, including cancer (13,26-29). 


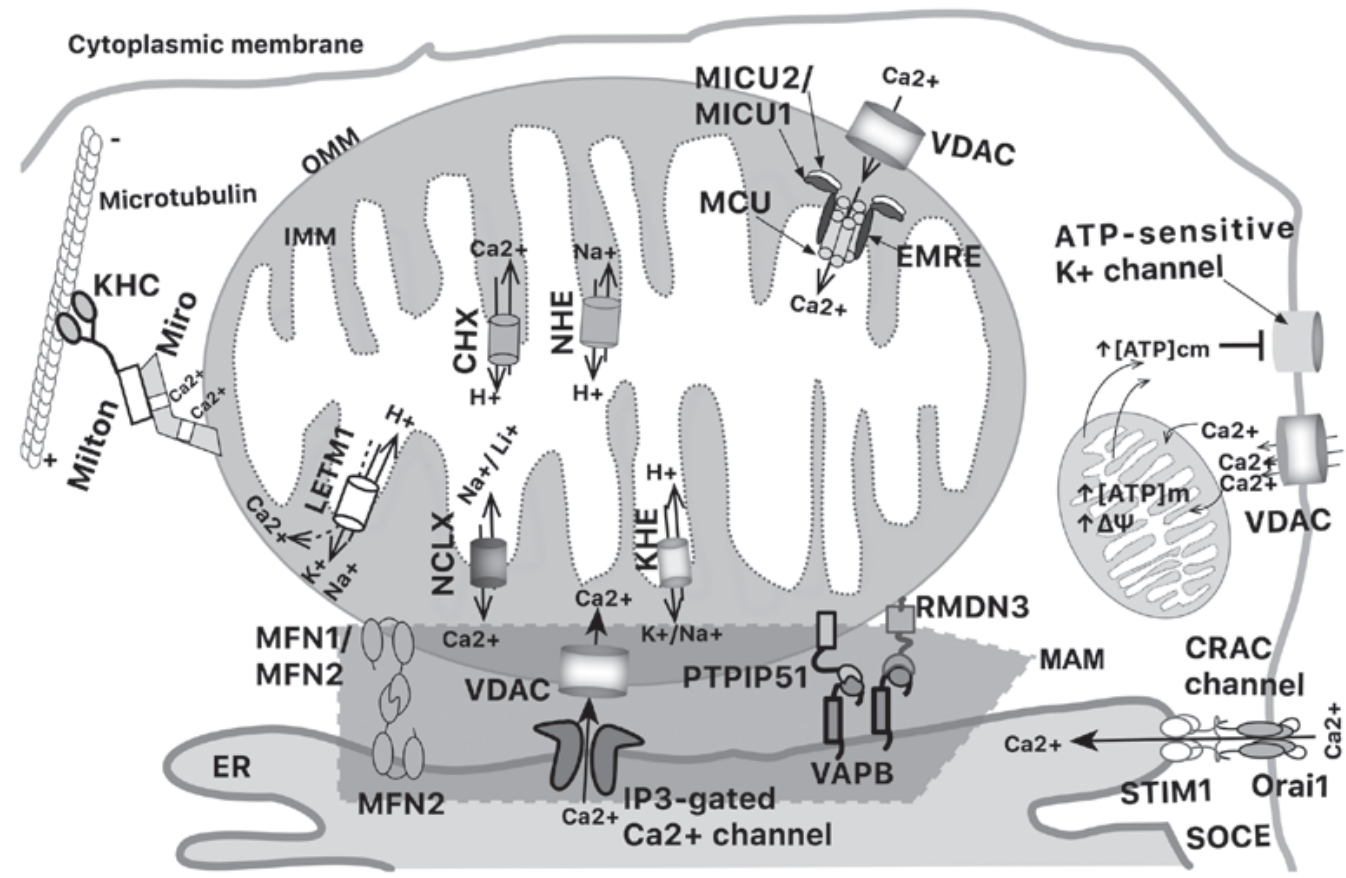

Figure 1. Schematic representation of mitochondrial calcium interplay. Calcium can be directly transported from the cytoplasmic membrane into mitochondria or ER using VDAC and CRAC channels. VDAC/MCU and STIM1 introduce calcium into mitochondria and ER, respectively. IP ${ }_{3}$ Rs export calcium from ER to mitochondria at MAMs where various pairs of molecules support the union between mitochondria and ER. A fine-tuning interplay exists among different cations that participate in mitochondrial calcium extrusion. Dotted arrow represents $\mathrm{pH}$-dependent transport of $\mathrm{Ca}^{2+}$. $\mathrm{CHX} \mathrm{Ca}^{2+} / \mathrm{H}^{+}$exchanger; $\mathrm{CRAC}$, calcium release-activated channels; EMRE, essential MCU regulator; ER, endoplasmic reticulum; $\mathrm{PP}_{3} \mathrm{R}$, inositol 1,4,5-trisphosphate receptor; KHC, kinesin heavy chain; KHE, mitochondrial $\mathrm{K}^{+} / \mathrm{H}^{+}$exchanger; LETM1, leucine zipper-EF-hand containing transmembrane protein 1 ; MAM, mitochondria-associated membrane; MCU, mitochondrial calcium uniporter; MICU1/2, mitochondrial calcium uptake 1 and $2 ; \mathrm{NCLX} \mathrm{Na}^{+} / \mathrm{Ca}^{2+}$ exchange; $\mathrm{NHE}, \mathrm{Na}^{+} / \mathrm{H}^{+}$exchanger; PTPIP51, protein tyrosine phosphatase interacting protein 51; RMDN3, regulator of microtubule dynamics 3; SOCE, store-operated Ca ${ }^{2+}$ entry channels; STIM1, stromal interaction molecule 1; VAPB, vesicle-associated membrane protein associated protein B; VDAC, voltage-dependent anion channels.

Notably, the ER supplies $\mathrm{Ca}^{2+}$ directly to mitochondria via the MAM through the use of $\mathrm{IP}_{3}$ receptors $\left(\mathrm{IP}_{3} \mathrm{Rs}\right)(13)$. $\mathrm{IP}_{3} \mathrm{Rs}$ are tetrameric ER-resident $\mathrm{Ca}^{2+}$ channels that release $\mathrm{Ca}^{2+}$ from the ER into the cytosol in response to $\mathrm{IP}_{3}$ (Fig. 1) (30). Three isoforms comprise the $\mathrm{IP}_{3} \mathrm{R}$ family and the majority of cell types express two or even all three isoforms. For example, secretory granules of human astrocytes can contain all three $\mathrm{IP}_{3} \mathrm{R}$ isoforms (31). Although, $\mathrm{IP}_{3} \mathrm{R}-1$ is the most widely expressed and appears to be ubiquitous in animal tissues, it can be highly expressed in cells from the mouse central nervous system (32). $\mathrm{IP}_{3} \mathrm{R}-2$ and -3 are highly expressed in human hematopoietic and lymphatic cells (33). In this regard, $\mathrm{IP}_{3} \mathrm{Rs}$ seem to be essential for constitutive $\mathrm{Ca}^{2+}$ release from the ER to mitochondria, in order to maintain sufficient mitochondrial NADH production to support mitochondrial bioenergetics. In DT40-KO cells, which is a chicken B cell line in which the three $\mathrm{IP}_{3} \mathrm{R}$ isoforms are genetically deleted, the absence of $\mathrm{Ca}^{2+}$ transfer inhibits pyruvate dehydrogenase and activates 5' AMP-activated protein kinase (AMPK), which activates pro-survival autophagy via a mammalian target of rapamycin (mTOR)-independent mechanism. AMPK phosphorylates substrates to limit anabolic pathways that consume ATP and to initiate catabolic pathways that support oxidative phosphorylation (OXPHOS) (34).

\section{Role of $\mathrm{Ca}^{2+}$ in mitochondrial function}

Increasing evidence has revealed how calcium regulates mitochondrial function. Notably, high glucose levels promote a sustained increase in $\left[\mathrm{Ca}^{2+}\right]_{\mathrm{m}}$, cytoplasmic calcium concentration $\left(\left[\mathrm{Ca}^{2+}\right]_{\mathrm{c}}\right)$ and insulin secretion; these effects can be abolished by inhibitors of voltage-gated $\mathrm{Ca}^{2+}$ channels in INS-1 pancreatic $\beta$-cells. The increase in calcium levels promotes the synthesis of mitochondrial ATP, accompanied by increased levels of NADH and NADPH cofactors (35). Calcium-associated activation of mitochondrial dehydrogenases, including pyruvate and 2-oxoglutarate dehydrogenase complexes, $\mathrm{NAD}^{+}$-isocitrate dehydrogenase and inorganic pyrophosphatase, may sustain the reduction of $\mathrm{NAD}^{+}$and $\mathrm{NADP}^{+}$cofactors. All these enzymes are highly sensitive to alterations in calcium concentration inside the mitochondrial matrix $(9,11,35,36)$. For example, $\left[\mathrm{Ca}^{2+}\right]_{\mathrm{m}}<1 \mathrm{mM}$ is required to induce the full activation of pyruvate dehydrogenase (PDH)-phosphate phosphatase, which removes the phosphate group from PDH-phosphate, and increases the proportion of active and dephosphorylated PDH. Two other examples include 2-oxoglutarate dehydrogenase that catalyzes the irreversible reaction of the oxidative decarboxylation of 2-oxoglutarate and $\mathrm{NAD}^{+}$-isocitrate dehydrogenase that responds to changes in $\left[\mathrm{Ca}^{2+}\right]_{\mathrm{m}}$ varying between 1 and $20 \mathrm{mM}(37)$.

Notably, in single islet $\beta$-cells, extracellular glucose concentrations $(3-30 \mathrm{mM})$ increase $[\mathrm{ATP}]_{\mathrm{m}}$ in the mitochondria located close to the cytoplasmic membrane $(\mathrm{cm})$. This phenomenon leads to increased $[\mathrm{ATP}]_{\mathrm{cm}}$, which is essential for sustained closure of the ATP-sensitive $\mathrm{K}^{+}$channels that additionally causes $\mathrm{Ca}^{2+}$ influx into the cell. The mitochondria located close to the cytoplasmic membrane also have access to a privileged elevation of $\left[\mathrm{Ca}^{2+}\right]_{\mathrm{cm}}$. This calcium enters 
mitochondria, progressively activating $\mathrm{Ca}^{2+}$-dependent mitochondrial enzymes to increase $[\mathrm{ATP}]_{\mathrm{m}}$ that establishes a feed-forward process (Fig. 1) (36).

Mitochondrial matrix calcium can also activate ATP synthesis and adenylate transport (38). The increase in [ATP] depends on the amplitude of $\mathrm{Ca}^{2+}$ elevations in the mitochondrial matrix and the availability of mitochondrial substrates. Notably, a $\mathrm{Ca}^{2+}$ increase induces a long-lasting effect that persists even after the elevation has finished, which denotes a cellular memory that allows prolonged metabolic activation in stimulated cells (11).

Activation of ATP synthesis by $\left[\mathrm{Ca}^{2+}\right]_{\mathrm{m}}$ is concomitantly accompanied by a rise in mitochondrial membrane potential, which is the driving force for $\mathrm{Ca}^{2+}$ accumulation (36,37). This has been shown in cerebellar granule neurons, where in vitro neuronal stimulation induced by mitochondrial depolarization with high concentrations of $\mathrm{KCl}$ results in the entry of cytosolic $\mathrm{Ca}^{2+}$ into the mitochondria (3). Conversely, a decrease in mitochondrial membrane potential inhibits $\left[\mathrm{Ca}^{2+}\right]_{\mathrm{m}}$ uptake (3).

In HL-1 cardiomyocytes, sustained elevation of intracellular $\left[\mathrm{Ca}^{2+}\right]$ can cause hypertrophy. During such $\mathrm{Ca}^{2+}$ elevations, mitochondria accumulate calcium rapidly, which induces the opening of permeability transition pores (PTP), matrix swelling, OMM rupture and cell death (39). High concentrations of calcium $(300 \mathrm{mM})$ decrease ATP production $>2$-fold in cardiomyocytic mitochondria; however, incubation of these mitochondria with $\mathrm{Ca}^{2+}$ and muscle fructose 1,6-bisphosphatase (FBP) allows recovery of ATP levels, thus suggesting that FBP blocks the inhibitory effects of high $\left[\mathrm{Ca}^{2+}\right]$ (39). Muscle FBP has two predominant oligomeric states that determine its subcellular localization. Only dimeric FBP interacts with mitochondria and protects them against stress stimuli (40). Therefore, as a survival mechanism associated with the elevation of calcium, cardiomyocytes promote the binding of FBP to mitochondria. FBP, in addition to being a regulatory enzyme of glyconeogenesis, can also join to mitochondria preventing their dysfunction by calcium stress. FBP interacts with mitochondrial proteins involved in regulating membrane permeability by reducing $\mathrm{Ca}^{2+}$-induced PTP opening; FBP also interacts with mitochondrial proteins involved in energy homeostasis, which causes stimulation of ATP synthesis (39).

Role of $\mathrm{Ca}^{2+}$ in mitochondrial dynamics

$\mathrm{Ca}^{2+}$ influx into mitochondria has important consequences on the organelles themselves. For example, $\mathrm{Ca}^{2+}$ influx through VDAC and MCU induces rapid mitochondrial fission by phosphorylation at serine 600 of the dynamin-related protein 1 (DRP1) in neurons (41). DRP1 also has GTPase activity and serves a critical role in mitochondrial fission (42). In addition, the increase in $\left[\mathrm{Ca}^{2+}\right]_{\mathrm{c}}$ promotes the translocation of DRP1 to mitochondria in cardiomyocytes and in cadmium-treated human and rat liver cells $(43,44)$. Mitochondrial fission events have been located at the MAM compartment (26), where $\mathrm{Ca}^{2+}$ is a critical regulator of mitochondrial morphology since mitochondrial $\mathrm{Ca}^{2+}$ overload leads to mitochondrial fragmentation, whereas mitochondrial $\mathrm{Ca}^{2+}$ depletion results in mitochondrial hyperfusion (45).

Mitochondria depend on microtubules for their intracellular motility via a $\mathrm{Ca}^{2+}$-regulated mechanism. This movement capacity of mitochondria allows appropriate distribution of these organelles for local ATP supply and $\mathrm{Ca}^{2+}$ buffering. Using this movement, mitochondria is settled in perinuclear clusters or in clusters near the cytoplasmic membrane. In this regard, the $\mathrm{KHC} / \mathrm{Milton} / \mathrm{Miro}$ complex regulates $\mathrm{Ca}^{2+}$-dependent mitochondrial motility. The Miro protein joins to the OMM. Miro contains a pair of EF-hand $\mathrm{Ca}^{2+}$-binding motifs that will permit interaction with the motor domain of kinesin-1 through the Milton adaptor protein (Fig. 1) (46). Calcium-dependent arrest of mitochondrial motility is required to position mitochondria where the cell needs $\mathrm{Ca}^{2+}$-buffering or an increased ATP supply, as has been observed in neurons and other cells $(46,47)$. For example, motility of astrocytic mitochondria is inversely related to intracellular calcium concentrations $\left(\left[\mathrm{Ca}^{2+}\right]_{\mathrm{i}}\right)$; elevated $\left[\mathrm{Ca}^{2+}\right]_{\mathrm{i}}$ immobilizes astrocytic mitochondria, whereas low $\left[\mathrm{Ca}^{2+}\right]_{\mathrm{i}}$ under resting conditions causes mitochondria to be highly mobile (47). The mitochondrial fission-fusion machinery is also associated with the mitochondrial motility machinery.

$\mathrm{Ca}^{2+}$ participation in mitochondrial dynamics also includes mitophagy, which is a highly specialized process that removes dysfunctional mitochondria. This has been observed in neurodegenerative diseases, and calcium dysregulation and ROS production are potential mitophagy inducers $(48,49)$. Mitophagy protects cells from damage that could occur from a disordered mitochondrial metabolism. Phosphatase and tensin homolog deleted on chromosome 10-induced kinase 1 (PINK1) is a mitochondrial protein that preserves mitochondrial integrity, and also participates in mitophagy activation. Upon mitochondrial depolarization, PINK1 and beclin 1 (BECN1) selectively relocalize to the surface of the damaged mitochondria, particularly at the MAM contact. This anchoring of PINK1 and BECN1 recruits proteins, such as ubiquitin and PARK2/Parkin, giving rise to autophagosome formation, thus resulting in mitophagy of damaged mitochondria (50). PINK1 localized at MAM also modulates mitochondrial calcium levels $(48,50)$.

\section{Calcium signals control cell migration and apoptosis}

In migrating eukaryotic cells, calcium signals control cell migration through the regulation of forward movement and cell adhesion (2). For example, $\mathrm{Ca}^{2+}$-influx channels regulate trailing edge contraction in the migration of growth factor-induced fibroblast cells and spontaneously polarized macrophages $(1,51)$. In particular, inhibition of the extracellular $\mathrm{Ca}^{2+}$ influx in RAW macrophages induces the loss of phosphoinositide 3-kinase (PI3K) activity at the leading edge, disassembly of filamentous actin (F-actin) and cessation of ruffling. $\mathrm{Ca}^{2+}$-sensitive enzyme protein kinase $\mathrm{Ca}(\mathrm{PKCa})$, which is an actin regulatory protein, is enriched at the leading edge of macrophages. This PKCa enrichment is affected by blockade of $\mathrm{Ca}^{2+}$ influx, inhibition of PI3K activity or F-actin depolymerization (51). PKCa can synergistically regulate migration by phosphorylating myosin, by regulating the cytoskeleton or by turning over integrin complexes (2).

Calcium signals, in addition to regulating forward movement, can also control cell adhesion. Pulsatile front retraction and cell adhesion of human umbilical vein endothelial cells are locally supported by $\mathrm{Ca}^{2+}$ pulses near the leading edge caused by ER $\mathrm{Ca}^{2+}$ depletion and stromal interaction molecule 1 (STIM1) activation. STIM1 likely acts locally on adhesion by enhancing $\mathrm{Ca}^{2+}$ influx and reloading 
Table I. Tumor suppressor proteins and oncoproteins that localize to the mitochondria-associated membrane.

A, Tumor suppressor proteins

\begin{tabular}{|c|c|c|}
\hline First author, year & Name & Reference \\
\hline Raturi et al,2016 & Thioredoxin-related transmembrane protein & (101) \\
\hline Nutt et al, 2002; Scorrano et al, 2003 & Bcl-2-associated X, apoptosis regulator & $(102,103)$ \\
\hline Nutt et al, 2002; Scorrano et al, 2003 & Bcl-2 antagonist/killer 1 & $(102,103)$ \\
\hline Echeverry et al, 2013 & $\mathrm{Bcl}-2$ related protein ovarian killer & (104) \\
\hline Giorgi et al, 2010 & Promyelocytic leukemia protein & $(105)$ \\
\hline Bononi et al, 2013 & Phosphatase and tensin homolog deleted on chromosome 10 & (106) \\
\hline Verfaillie et al, 2012 & RNA-dependent protein kinase-like ER kinase & $(107)$ \\
\hline Li et al, 2008 & ER-associated apoptosis-involved protein & $(108)$ \\
\hline Seervi et al, 2013 & ER oxidoreductin- $1 \alpha$ & $(58)$ \\
\hline Iwasawa et al, 2011 & Fission, mitochondrial 1 & $(109)$ \\
\hline Iwasawa et al, 2011 & B cell receptor-associated protein 31 & (109) \\
\hline Namba et al, 2013 & Cell death inducing p53 target 1 & $(110)$ \\
\hline
\end{tabular}

B, Anti-apoptotic molecules

Name

Reference

Betz et al, 2013

Mammalian target of rapamycin complex 2

Monaco et al, 2015

$\mathrm{Bcl}-2$

Bcl-2, B-cell lymphoma 2; ER, endoplasmic reticulum.

ER $\mathrm{Ca}^{2+}$ stores in the front of the cell to permit local $\mathrm{Ca}^{2+}$ pulses (Fig. 1) (2). Cancer cell migration will be described below.

$\mathrm{Ca}^{2+}$ transfer between the ER and mitochondria represents a critical signal in the induction of apoptosis (28). One of the best-characterized mechanisms is via the p53 pathway. The p53 protein is a master tumor-suppressor protein that promotes apoptosis through two mechanisms: As a transcription factor, p53 controls cell-death programs within the nucleus (52), or through a $\mathrm{Ca}^{2+}$-dependent mechanism modeling MAM cross talk. The p53 protein interacts with sarco/ER $\mathrm{Ca}^{2+}$-ATPase (SERCA) pumps causing an alteration in their oxidative state. This leads to an increased $\mathrm{Ca}^{2+}$ load that is transferred directly to the mitochondria that causes changes in mitochondrial morphology and induction of apoptosis (28). Depolarization of the mitochondria triggered by high $\mathrm{Ca}^{2+}$ levels is followed by a decrease in ATP synthesis, leading to cell death (39). Morphological alterations in mitochondria caused by $\mathrm{Ca}^{2+}$ overload result in the opening of PTPs, mitochondrial fragmentation and cytochrome $c$ release, which are all factors that lead to apoptotic cell death (28).

\section{Calcium interplay is remodeled by cancer: Alterations in MAM and mitochondrial dynamics}

Cancer alters the architecture of MAM to support survival and aggressiveness

The present review discussed the mechanisms where the role of $\mathrm{Ca}^{2+}$ is essential for sustaining cellular homeostasis.
However, in cancer, increasing evidence has revealed a link between alterations in mitochondrial $\mathrm{Ca}^{2+}$ homeostasis and malignant phenotypes, including cell survival, invasiveness, migration, apoptosis evasion and drug resistance $(53,54)$.

Notably, MAM domains are involved in various important processes in tumor cells that allow their survival, including adhesion, motility, invasion, metastasis, autophagy and apoptosis $(28,55,56)$. Cancer cells remodel MAM architecture by modifying the expression levels of ER and mitochondrial $\mathrm{Ca}^{2+}$ channel proteins, their associated binding partners, or their regulators (53). For example, in HeLa cells, a detailed microscopy study demonstrated that a fraction of the mitochondrial pool is in close contact with the ER cisternae in these highly localized MAM domains (12). These contacts are also increased between mitochondria and ER in prostate cancer cells that have acquired cancer stem-like properties (57).

Numerous tumor suppressor proteins have been demonstrated to be localized to the ER and MAMs where they regulate cell death (Table I). Some of these suppressor proteins directly affect calcium flux; for example, silencing of ER oxidoreductin-1 $\alpha$ significantly inhibits calcium release from the ER, inducing cell death (58). A reduction in the $\mathrm{Bcl}-2 / \mathrm{Bcl}-2$-associated $\mathrm{X}$, apoptosis regulator ratio also leads to $\mathrm{ER} \mathrm{Ca}^{2+}$ depletion, which induces cytosolic $\mathrm{Ca}^{2+}$ overload and causes the loss of mitochondrial membrane potential (59).

$\mathrm{IP}_{3} \mathrm{R}-3$ is an oncoprotein differentially expressed in colorectal carcinoma that is absent in normal colorectal mucosa (Fig. 2). Increased expression of $\mathrm{IP}_{3} \mathrm{R}-3$ is strongly correlated with metastasis and decreased 5-year survival (60). 
In addition, $\mathrm{IP}_{3} \mathrm{R}-3$, but not the type 1 or 2 isoforms, is overexpressed in gastric cancer cell lines established from malignant ascites (61). Conversely, $\mathrm{IP}_{3} \mathrm{R}-3$ is involved in mediating pro-apoptotic $\mathrm{Ca}^{2+}$ signals from the ER to mitochondria in HeLa cells (62). Although $\mathrm{IP}_{3} \mathrm{R}-3$ colocalizes more closely with mitochondria more efficiently transmitting $\mathrm{Ca}^{2+}$ signals, in colorectal cancer, $\mathrm{IP}_{3} \mathrm{R}-3$ expression inhibits rather than promotes apoptosis, possibly by participating in a localized signaling domain mechanism that remains to be clarified (60).

Some anti-apoptotic molecules are also localized to the MAM and modulate cell death (Table I). mTOR complex 2 (mTORC2) controls MAM integrity and mitochondrial function via protein kinase B (AKT)-mediated phosphorylation of $\mathrm{IP}_{3} \mathrm{R}$ and hexokinase 2 (55). In non-small cell lung carcinoma (NSCLC) cells resistant to erlotinib, a tyrosine kinase inhibitor (TKI), epidermal growth factor receptor (EGFR)-TKI resistance is reduced in response to rituximab, an anti-cluster of differentiation 20 monoclonal antibody. Briefly, NSCLC cells that carry the EGFR T790M-mutation are resistant to erlotinib treatment; however, the addition of rituximab significantly inhibits proliferation and cell survival. The proposed mechanism involves a reduction in the phosphorylation of EGFR, mTOR and mTORC2, which is associated with inhibition of mTORC2 localization to MAM; consequently, cell growth is inhibited (63).

Bcl-2 and Bcl-extra large (Bcl-XL) proteins exert part of their anti-apoptotic functions by directly binding to ER-localized $\mathrm{IP}_{3} \mathrm{Rs}$ and to OMM-localized VDAC1, respectively. The joining of $\mathrm{Bcl}-2$ and $\mathrm{Bcl}-\mathrm{XL}$ to these $\mathrm{Ca}^{2+}$ transport systems will negatively affect $\mathrm{Ca}^{2+}$ transfer and apoptosis (Fig. 2) (62).

\section{Calcium levels affect mitochondrial dynamics}

To satisfy cellular demands, mitochondria continually change their shape and function; therefore, the combined actions of fusion and fission determine the balance between oxidative and glycolytic metabolisms. In cancer, the ability of tumor cells to survive has been associated with unbalanced mitochondrial dynamics, as it has been demonstrated in lung, pancreatic, breast and oncocytic thyroid cancers, among others (64-67). Notably, feedback regulation has been established between calcium signaling and mitochondrial dynamics to coordinate regulation of numerous tumor cellular processes (68). For example, in melanoma cells treated with three compounds, a mitochondrial $\mathrm{Na}^{+} / \mathrm{Ca}^{2+}$ exchanger inhibitor (CGP-37157) and two OXPHOS inhibitors (antimycin A and FCCP), a fast and persistent rise in $\left[\mathrm{Ca}^{2+}\right]_{\mathrm{m}}$ is detected. These compounds increase tumor necrosis factor-related apoptosis-inducing ligand (TRAIL) sensitivity, switching from apoptosis to nonapoptotic cell death. The $\left[\mathrm{Ca}^{2+}\right]_{\mathrm{m}}$ overload increases mitochondrial fragmentation, whereas $\left[\mathrm{Ca}^{2+}\right]_{\mathrm{m}}$ removal induces mitochondrial hyperfusion. Notably, both actions affecting mitochondrial dynamics exacerbate TRAIL-induced mitochondrial rearrangements and cytotoxicity. This study indicated that an appropriate level of mitochondrial calcium is essential for maintaining mitochondrial dynamics associated with tumor cell survival (45).

In liver cancercells, increased $\left[\mathrm{Ca}^{2+}\right]_{c}$ promotes mitochondrial fission by upregulating DRP1 and fission, mitochondrial 1 genes via nuclear factor of activated T cells 2 (NFATC2) and c-Myc activation, respectively. NFATC 2 is a calcium responsive transcription factor that it is overactivated in several types of cancers (68).

MFN2 is a protein that promotes mitochondrial fusion. This molecule is downregulated in patients with liver cancer and low levels of MFN2 are associated with a poorer prognosis. Notably, MFN2 expression is lower in tumor tissues than in adjacent noncancer tissues. In vitro upregulation of MFN2 in the liver cancer cell line HepG2 triggers $\mathrm{Ca}^{2+}$ influx from the ER into mitochondria, increasing $\left[\mathrm{Ca}^{2+}\right]_{\mathrm{m}}$, ROS production and reducing mitochondrial membrane potential; all these phenomena lead to tumor cell apoptosis. These findings highlight the role of MFN2 as a tumor suppressor protein (69). Furthermore, it has been described that microRNA (miR)-761 binds the 3'-untranslated region of MFN2. The upregulation of miR-761 is associated with MFN2 downregulation; therefore, it may support cell proliferation, cell migration and invasiveness of liver tumors. Inhibition of miR-761 affects mitochondrial function and inhibits cell proliferation, migration and invasion of liver cancer in vivo and in vitro (Fig. 2) (70).

\section{Mitochondrial calcium and mitoflashes in epitheli- al-to-mesenchymal transition}

$\mathrm{Ca}^{2+}$ signals regulate proliferation in a spatial- and temporal-dependent manner. Whereas nuclear $\mathrm{Ca}^{2+}$ signals may regulate cell proliferation, the increase of $\left[\mathrm{Ca}^{2+}\right]_{m}$ may regulate apoptosis in epithelial cells $(62,71)$. Nevertheless, calcium signaling may support loss of the balance between cell proliferation and apoptosis, favoring cellular proliferation and inhibiting apoptosis in cancer. Enhanced cytosolic $\mathrm{Ca}^{2+}$ signaling has been suggested to contribute to the transition from normal colonic epithelial cells to adenoma, which finally transforms to carcinoma (60). The epithelial-to-mesenchymal transition (EMT) is a critical process during progression of tumor metastasis (72). The loss of cell-cell adhesion is promoted by the transformation of polarized epithelial cells into highly motile mesenchymal cells (73). In MCF-7 breast cancer cells, inhibition of the Oct4 transcription factor or treatment with transforming growth factor $\beta 1$ (TGF $\beta 1$ ) promotes migration and invasion. This EMT induction is accompanied by upregulation of STIM1 and ORAI calcium release-activated calcium modulator 1 (Orai1), two major components of store-operated $\mathrm{Ca}^{2+}$ entry channels (SOCE). STIM1 serves as a $\mathrm{Ca}^{2+}$-sensor, and Orai1 is an essential pore-forming component of SOCE channel (Fig. 2) (74). Blockage of $\mathrm{Ca}^{2+}$ influx by silencing STIM1 partially rescues the EMT initiated by Oct4 downregulation, indicating that other calcium channels possibly take part in increased calcium influx (72). The SOCE pathway is activated by the release of $\mathrm{Ca}^{2+}$ from the ER that causes the oligomerization of STIM1. STIM1 binds the plasma membrane $\mathrm{Ca}^{2+}$ channel Orai, which causes it to open (75). Nevertheless, this mechanism requires functional mitochondria and the inhibition of MCU slowly deactivates SOCE (6).

In addition to TGF $\beta$, EGF is associated with EMT induction in the breast cancer cell line MDA-MB-468, through upregulating the mRNA expression levels of the ATP-binding cassette $\mathrm{C} 3$ (ABCC3). The EGF-induced transcriptional upregulation of $\mathrm{ABCC} 3$ is dependent on calcium signals. 


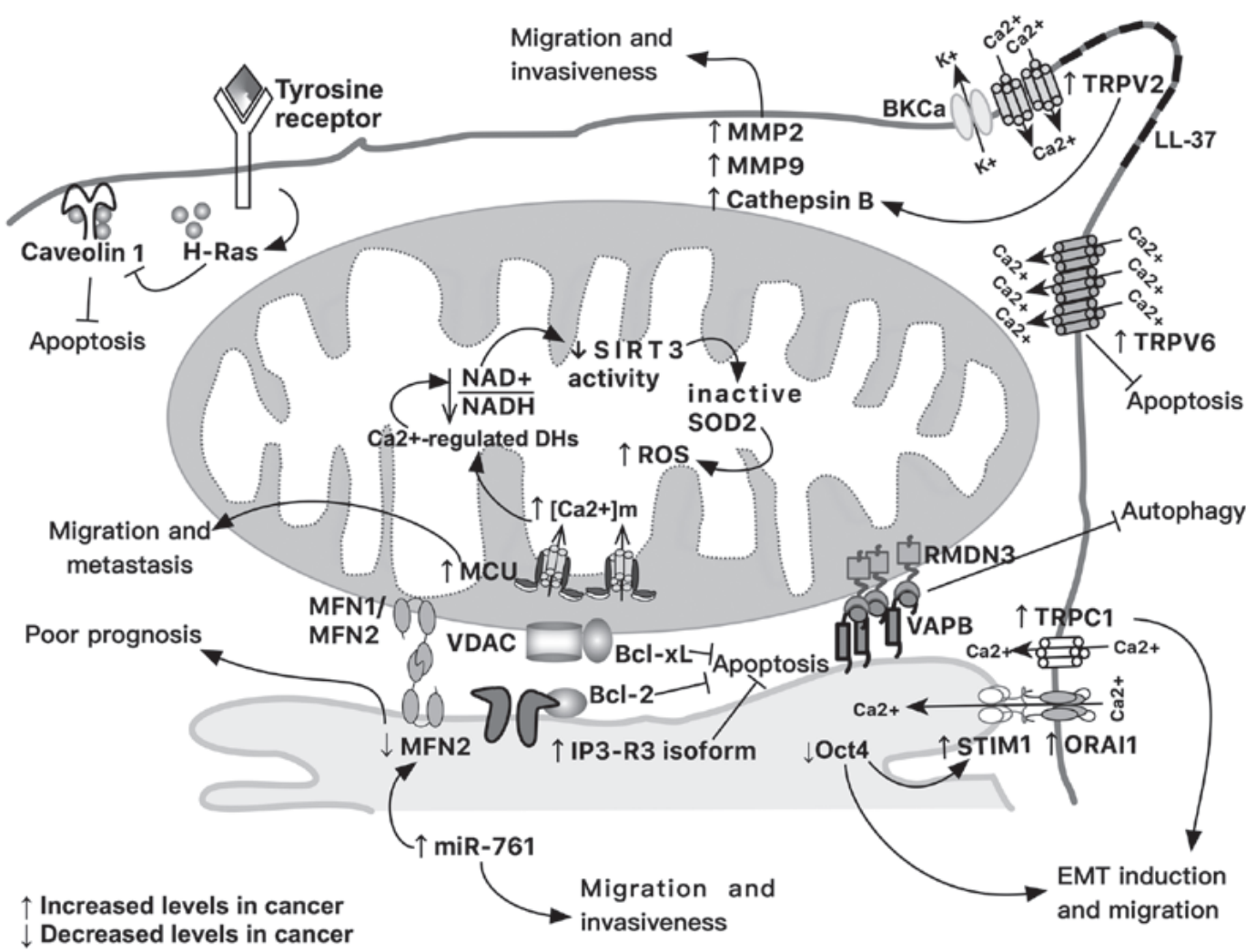

Figure 2. Tumor modifications in mitochondrial calcium interplay that support invasiveness, migration, apoptosis evasion and induction of epithelial-to-mesenchymal transition. Note that not all these modifications occur at the same time and in the same tumor. MMP, matrix metalloproteinase; BKCa, large-conductance $\mathrm{Ca}^{2+}$-activated $\mathrm{K}^{+}$channel; DH, dehydrogenase; EMT, epithelial-to-mesenchymal transition; Oct4, octamer-binding transcription factor 4; SIRT3, sirtuin 3; SOD2, superoxide dismutase 2; TRPC1, transient receptor potential cation channel C1; TRPV, transient receptor potential cation channel subfamily vanilloid

This calcium-dependent regulation of $\mathrm{ABCC} 3$ occurs via the calcium permeable ion channel transient receptor potential cation channel C1 (TRPC1) (76). Furthermore, a previous study suggested that the TRPC1 channel contributes to Orai1-mediated $\mathrm{Ca}^{2+}$ influx in the EMT of MDA-MB-468 cells (Fig. 2) (77). Additionally, TRPC1-mediated calcium influx has been linked to EGF-stimulated EGFR activation in non-small cell lung cancer cells by promoting cellular proliferation (78).

Mitochondrial calcium levels also regulate certain discrete and stochastic mitochondrial events called mitoflashes, which comprise a burst of superoxide production accompanied by transient depolarization and alkalization in the mitochondrial matrix (79). Transient opening of the mitochondrial PTP (mPTP) seems to precede the mitoflash. Mitoflash biogenesis can be activated by $\left[\mathrm{Ca}^{2+}\right]_{\mathrm{m}}$ increase, ROS and mPTP promoters, but suppressed by ROS scavengers and MPTP inhibitors (80). Hyperosmotic or oxidative stress and ROS-dependent apoptosis are associated with an increased frequency of mitoflashes, which arises as a bioindicator of cellular dysfunction (81). The frequency of mitoflashes has been reported to transiently increase during the early stages of somatic cell reprogramming, establishing a link between the role of mitoflashes and the acquisition of pluripotency (82). Other factors that may modulate mitoflash occurrence rate are aging and cancer (80).

Proteins such as EF-hand domain family member D (EFHD), solute carrier family 25 member 25 (SLC25A25), solute carrier family 25 member 23 and MICU1 are considered mitoflash activators. Notably, all of them contain $\mathrm{Ca}^{2+}$-binding motifs. In addition, LETM1 is considered a mitoflash inhibitor that responds to hyperosmotic stress (Fig. 3). Recently, optic atrophy 1 protein (OPA1) has emerged as a regulator of the occurrence of mitoflashes, which is an independent process from fusion; OPA1 stabilizes respiratory chain supercomplexes in a conformation that enables mitochondria to compensate a fall in mitochondrial membrane potential by an explosive-pH flash (Fig. 3) (81).

EFHD1 has been involved in the alteration of mitochondrial function to control cell survival or neural differentiation. EFHD1 is also known as mitocalcin and has $\mathrm{Ca}^{2+}$ binding characteristics; this molecule acts as a $\mathrm{Ca}^{2+}$ sensor enhancing mitoflash responses (79). Another example is SLC25A25, which functions as a $\mathrm{Ca}^{2+}$-regulated shuttle of ATP- $\mathrm{Mg}^{2+}$ and pyrophosphate across the IMM. SLC25A25 has been reported to be upregulated by 3.2 -fold in the RC77T/E human prostate tumor cell line (83). In this sense, the expression of the long noncoding RNA relating to SLC25A25 (SLC25A25-AS1), which inhibits SLC25A25 translation, is significantly decreased in tumor tissues and serum of patients with colorectal cancer. In vitro overexpression of SLC25A25-AS1 significantly inhibits proliferation and colony formation in colorectal cancer cell lines; in addition, downregulation of SLC25A25-AS1 enhances chemoresistance and promotes the EMT process (84).

\section{Calcium: A critical regulator of tumor migration, inva- siveness and metastasis}

$\mathrm{Ca}^{2+}$ signals regulate polarization, speed and the direction of movement of migrating cells. Cancer cells migrate by applying 


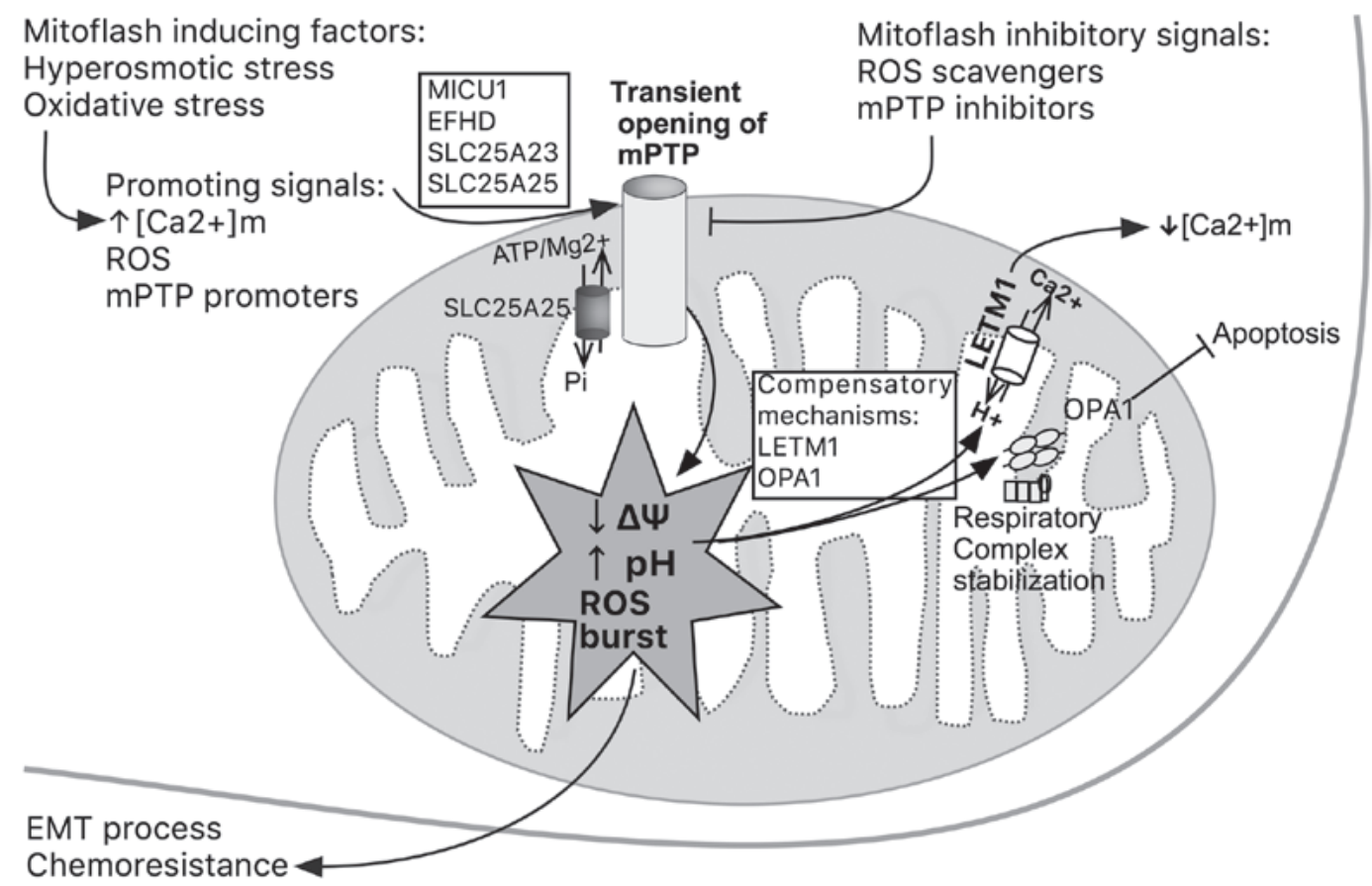

Figure 3. Schematic diagram of mitoflash biogenesis. Inducing factors promote signals that may act through various proteins. These proteins have a Ca ${ }^{2+}$-binding site and participate in the transient opening of mPTP just before mitoflash occurrence. Subsequently, LETM1 and OPA1 proteins conform different compensatory mechanisms to avoid apoptosis or to diminish $\left[\mathrm{Ca}^{2+}\right]_{\mathrm{m}}$. An increased frequency of mitoflashes has been associated with EMT and chemoresistance. $\left[\mathrm{Ca}^{2+}\right]_{\mathrm{m}}$, mitochondrial $\mathrm{Ca}^{2+}$ concentration; EFHD, EF-hand domain family member D; EMT, epithelial-to-mesenchymal transition; mPTP, mitochondrial permeability transition pore; OPA1, optic atrophy 1 protein; SLC25A25, solute carrier family 25 member 25.

rearward forces against extracellular media. Freely migrating cancer cells move by inducing the formation of lamellipodia that are the extension of leading edge protrusions (85). Contractility-driven bleb formation has recently emerged as another mechanism of motility in mesenchymal precursors (86). Two sublines of WC256 carcinosarcoma cells (LC and BC) were transformed to observe mesenchymal migration and ameboid migration, and to find differences in electrotactic motility. LC and BC WC256 cells can efficiently drive electrotactic migration by forming lamellipodia and membrane blebs, respectively (87). Lamellipodia attach to the substratum, and contraction of the trailing rear edge moves the cell toward the lamellipodia. Blebs, on the other hand, are cellular protrusions expanded by hydrostatic pressure generated by a contractile actomyosin cortex. Bleb location appears to be directly controlled by the Rho pathway and by alterations in intracellular $\mathrm{Ca}^{2+}$ concentrations (87). Membrane rigidity is increased at the leading edge of pseudopodia and retracting tail in breast cancer cell lines by locally binding LL-37 to cytoplasmic membrane. LL-37 is a peptide released from the C-terminus of the human cathelicidin antimicrobial protein hCAPT18. LL-37 membrane binding activates PI3K/AKT signaling. Subsequently, AKT induces the recruitment of the transient receptor potential cation channel subfamily vanilloid member 2 (TRPV2) transporter from intracellular vesicles to plasma membrane of pseudopodia (Fig. 2). TRPV2 increases calcium that is accompanied by $\mathrm{K}^{+}$efflux through the $\mathrm{BKCa}$ channel (88). These local $\mathrm{Ca}^{2+}$ signals govern forward movement by regulating lamellipodia retraction and strengthen local adhesion to the extracellular matrix. Each $\mathrm{Ca}^{2+}$ pulse triggers contraction of actin filaments that activates myosin light-chain kinase and myosin II behind the leading edge (85). Activation of $\mathrm{Ca}^{2+}$-dependent kinases can also indirectly influence actin dynamics (51).

MCU upregulation significantly increases migration in vitro in MCF-7 breast cancer cells. Consistently, MCU protein levels are increased in biopsy samples from breast cancer patients who present with metastasis (Fig. 2) (89). Blocking $\mathrm{Ca}^{2+}$ influx using $\mathrm{Ni}^{2+}$ inhibits migration of mouse $4 \mathrm{~T} 1$ and human MDA-MB-231 breast tumor cells, highlighting a link between $\mathrm{Ca}^{2+}$ influx and migration (1).

Metastasis is a multistep process where cancer cells from a primary tumor site spread to distant organs and form new tumors, and calcium is a critical regulator of this process $(74,90)$. Using matrix metalloproteinases (MMPs) and cathepsins, invasive cells degrade surrounding tissue, and $\mathrm{Ca}^{2+}$ influx can affect the activity of these enzymes. In human prostate cancer, the development and progression of cancer to an aggressive castration-resistant phenotype are characterized by de novo expression of the TRPV2 channel. The role of TRPV2 is to maintain elevated cytosolic $\mathrm{Ca}^{2+}$ and to induce expression of MMP2, MMP9 and cathepsin B, enhancing a cell migration-invasive phenotype (Fig. 2) (91).

The metastatic capacity of tumor cells is also enhanced by upregulation of MCU expression.MCUincreases mitochondrial $\mathrm{Ca}^{2+}$ uptake, which promotes ROS production, favoring a metabolic shift from oxidative to glycolytic metabolism. For example, MCU overexpression promotes MMP2 expression and cell motility of liver cancer metastasis in a nude mouse model, where intrahepatic and distal lung metastasis are promoted through a ROS-activated c-Jun N-terminal kinase pathway (54). Briefly, mitochondrial $\mathrm{Ca}^{2+}$ elevation increases the activity of $\mathrm{Ca}^{2+}$-sensitive dehydrogenases, which diminishes the $\mathrm{NAD}^{+} / \mathrm{NADH}$ ratio. The $\mathrm{NAD}^{+}$-dependent 
deacetylase activity of sirtuin 3 (SIRT3) deacetylates superoxide dismutase 2 (SOD2), and the deacetylated and active form of SOD2 decreases ROS levels. However, low levels of $\mathrm{NAD}^{+}$, caused by $\mathrm{Ca}^{2+}$-sensitive dehydrogenases, inhibit SIRT3 activity, and the inactive form of SOD2 allows accumulation of ROS, which activates the c-Jun N-terminal kinase pathway (Fig. 2) (54). Furthermore, $\left[\mathrm{Ca}^{2+}\right]_{\mathrm{m}}$ levels are also increased in HepG2 cells that are exposed to high glucose levels (33 mM). Nevertheless, when MCU is inhibited, high glucose levels induce decreased generation of ROS and protection against inflammatory effects (92). Silencing MCU in cultured HeLa cells severely abrogates mitochondrial $\mathrm{Ca}^{2+}$ uptake, whereas mitochondrial respiration and membrane potential remain fully intact (17). Under these conditions, an oxidative metabolism might be favored and cell motility could be diminished.

The suppression of $\mathrm{Ca}^{2+}$ influx inhibits the AKT pathway in breast cancer cells (4T1, TUBO-P2J and HCC70 cell lines), thus resulting in the prevention of migration (90). Higher MCU expression has also been detected in MDA-MB-231 cells compared with in MCF-7 cells (89). MDA-MB-231 cells, which are more invasive than other breast cancer cells (4), have an elevated $\left[\mathrm{Ca}^{2+}\right]_{\mathrm{m}}$ uptake that is essential for the metabolic shift from oxidative to glycolytic metabolism that occurs during cancer metastasis (89). miR-340 can target and inhibit MCU, which consequently decreases $\left[\mathrm{Ca}^{2+}\right]_{\mathrm{m}}$ accumulation, metastatic cell motility and the matrix invasiveness of breast cancer cells (89). Additionally, STIM1 and Orail inhibition reduces serum-induced in vitro cell migration and in vivo metastasis formation of MDA-MB-231 breast cancer cells (74). Molecular components of the SOCE also regulate breast cancer metastasis by replenishing depleted $\mathrm{ER} \mathrm{Ca}^{2+}$ reserves. Inhibition of SERCA with cyclopiazonic acid or by agonist stimulation with ATP (77), or signaling mechanisms such as activated G-protein-coupled or tyrosine kinase receptors (4), may deplete ER $\mathrm{Ca}^{2+}$ stores. As further proof, inhibition of MCU by ruthenium red or specific small interfering (si)RNAs induces mitochondrial depolarization in MDA-MB-231 cells, which inhibits SOCE through CRAC channels and abrogates cancer cell migration (4).

\section{Mitochondrial calcium in tumor apoptotic failure and tumor autophagy}

Tumor cells have developed mechanisms where alterations in mitochondrial metabolism inhibit the intrinsic apoptotic pathway. In this context, the oncoprotein Ras promotes the failure of mitochondrial-dependent apoptosis, which induces neoplasia via an interaction with caveolin-1 (Cav-1). This tumor suppressor directly regulates $\mathrm{Ca}^{2+}$ influx machineries and the $\mathrm{Ca}^{2+}$-dependent apoptotic pathway. Cav-1 is a plasma membrane protein that also acts as a scaffolding protein for signaling molecules, including $\mathrm{Ca}^{2+}$-signaling members and Ras. Ras proteins are GTPases activated by receptor tyrosine kinases that transduce extracellular signals to the nucleus. In $3 \mathrm{~T} 3 \mathrm{NIH}$ fibroblasts transformed with a retrovirus expressing the oncogenic $\mathrm{H}-\mathrm{Ras}\left(\mathrm{H}-\mathrm{Ras}_{12 \mathrm{~V}}\right)$, it was revealed that $\mathrm{H}-\mathrm{Ras}_{12 \mathrm{~V}}$ accumulates at the MAM and plasma membrane-associated membranes (PAM), causing altered intracellular $\mathrm{Ca}^{2+}$ homeostasis. This compartmentalization of H-Ras compromises the cooperation between MAM and PAM, promoting the loss of Cav-1 (Fig. 2) (56).

Another example includes BRAF mutations that can reprogram melanoma metabolism. Briefly, BRAF inhibitors (BRAFi) hamper glucose uptake prior to the complete elimination of melanoma tumor cells. BRAFi-treated melanomas rapidly became OXPHOS-dependent to survive. BRAFi induces increased mitochondrial activity and biogenesis, and an increased capacity for mitochondrial $\mathrm{Ca}^{2+}$ buffering associated with mitochondrial network remodeling. A close interaction between the ER and mitochondria in BRAFi-exposed melanoma facilitates mitochondrial $\mathrm{Ca}^{2+}$ uptake after its release from the ER that prevents ER-mediated cell death (93). Furthermore, the inhibition of $\mathrm{Ca}^{2+}$ transfer from the ER to mitochondria may preserve mitochondrial integrity and protect against $\mathrm{Ca}^{2+}$-mediated apoptosis in human malignant pleural mesothelioma. A severe dysregulation of $\mathrm{Ca}^{2+}$ signaling is associated with resistance to apoptotic stimuli in mesothelioma cell lines and short-term cell cultures obtained from patients with malignant pleural mesothelioma (94).

The upregulation of some calcium transporters or their regulators has also been associated with resistance to apoptosis. Upregulation of MCU regulator 1 (MCUR1) has been associated with increased survival of liver cancer cells. MCUR1 overexpression indirectly inhibits mitochondrial-dependent intrinsicapoptosisdue to AKT/MDM2 proto-oncogene-mediated p53 degradation by the elevated production of mitochondrial ROS (95). Another example includes TRPV6, which is a highly selective $\mathrm{Ca}^{2+}$ channel involved in prostate carcinogenesis. Increased expression of TRPV6 is strongly correlated with cancer progression and with the resistance to apoptosis observed in hormone-sensitive prostate cancer cells (Fig. 2) (96). These aforementioned studies refer to the failure of apoptotic machinery that may favor phenotypes that resist traditional chemotherapy treatments.

Autophagy is a conserved process for the delivery of cellular material to lysosomes for degradation. This process recycles molecules for the synthesis of proteins, nucleic acids, lipids and carbohydrates, or prevents accumulation of protein aggregates and damaged organelles, maintaining cellular homeostasis (30). Intracellular levels of calcium have also been identified as a potential regulator of autophagy. This process can be induced by rapamycin and Torin 1; both molecules selectively inhibit mTOR. Alternatively, starvation can induce autophagy; this process is more complex but it also involves mTOR and various upstream nutrient-sensing molecules, including AMPK and calcium/calmodulin-dependent protein kinase kinase $\beta$ (CAMKK- $\beta)$ (13). In HeLa cells, $\mathrm{Ca}^{2+}$ mobilizing agents (ionomycin, ATP and thapsigargin) stimulate autophagy via CAMKK, which directly activates AMPK to inhibit mTOR (97). In addition, $\mathrm{Ca}^{2+}$ signaling promotes increased mitochondrial fission that leads to autophagy in liver cancer cells (68).

Previous studies have reported that disruption of $\mathrm{IP}_{3} \mathrm{R}$-mediated $\mathrm{Ca}^{2+}$ deliverystimulates autophagy invarioustypes of cancer $(98,99)$. In this context, vesicle-associated membrane protein-associated protein B (VAPB), an integral ER protein, binds to the regulator of microtubule dynamics 3 (RMDN3), an OMM protein, to form one set of tethers. Under non-stressing 
conditions, VAPB and RMDN3 overexpression favors the tether between the ER and mitochondria, thus inhibiting autophagy (Fig. 1); however, blocking the ER-mitochondria $\mathrm{Ca}^{2+}$ exchange using MCU-targeted antagonist siRNAs abrogates the effect of VAPB and RMDN3 overexpression, favoring autophagy. This highlights the role of VAPB-RMDN3 in ER-mitochondria $\mathrm{Ca}^{2+}$ delivery (13). Paradoxically, starvation-induced autophagy requires $\mathrm{Ca}^{2+}$ release from sensitized $\mathrm{IP}_{3} \mathrm{Rs}$ (30), thus suggesting that the autophagy process depends on spatial and temporal parameters of $\mathrm{Ca}^{2+}$ signaling, in addition to nutrient status and the availability of growth factors (99). Autophagy favors cancer development due to the energetic supply provided by organelle degradation typically driven by this process, which allows tumor cells to become resistant to stressing conditions, such as anticancer therapies. Therefore, autophagy inhibition has emerged as a potential cancer treatment strategy (100).

\section{Conclusions}

Through several mechanisms, mitochondria serve an essential role in maintaining cellular calcium levels. These processes are meticulously regulated because calcium acts as a trigger of regulatory cascades that affect the mitochondria themselves and, in consequence, metabolism, migration and cell survival.

Tumor cells may remodel the systems that maintain cellular calcium homeostasis, in order to promote their survival and metastasis. Understanding the integral metabolic importance of $\mathrm{Ca}^{2+}$ signaling in tumor cells, which includes the participation of various organelles, will allow the development of numerous therapies that may benefit patients with cancer.

\section{Acknowledgements}

Not applicable.

\section{Funding}

No funding was received.

\section{Availability of data and materials}

Not applicable.

\section{Authors' contributions}

SRG conceived, designed and wrote the manuscript. HPG was involved in writing and critically reviewing the manuscript, and figure design.

\section{Ethics approval and consent to participate}

Not applicable.

\section{Patient consent for publication}

Not applicable.

\section{Competing interests}

The authors declare that they have no competing interests.

\section{Authors' information}

Dr Susana Romero-Garcia, Department of Chronic-Degenerative Diseases, National Institute of Respiratory Diseases 'Ismael Cosío Villegas', Tlalpan 4502, Col. Sección XVI, CP 14080 Mexico City, Mexico. Phone: (+52-55) 5487-1703; Fax: (+52-55) 5665-4623. ORCID: 0000-0003-4539-0578. Dr Heriberto Prado-Garcia, Department of Chronic-Degenerative Diseases, National Institute of Respiratory Diseases 'Ismael Cosío Villegas', CP 14080 Mexico City, Mexico. ORCID: 0000-0002-4932-3244

\section{References}

1. Yang $\mathrm{S}$ and Huang XY: $\mathrm{Ca}^{2+}$ influx through L-type $\mathrm{Ca}^{2+}$ channels controls the trailing tail contraction in growth factor-induced fibroblast cell migration. J Biol Chem 280: 27130-27137, 2005.

2. Tsai FC, Seki A, Yang HW, Hayer A, Carrasco S, Malmersjö S and Meyer T: A polarized $\mathrm{Ca}^{2+}$, diacylglycerol and STIM1 signalling system regulates directed cell migration. Nat Cell Biol 16: 133-144, 2014.

3. Xiong J,CamelloPJ, Verkhratsky A and Toescu EC: Mitochondrial polarisation status and $\left[\mathrm{Ca}^{2+}\right]_{\mathrm{i}}$ signalling in rat cerebellar granule neurones aged in vitro. Neurobiol Aging 25: 349-359, 2004.

4. Tang S, Wang X, Shen Q, Yang X, Yu C, Cai C, Cai G, Meng X and Zou F: Mitochondrial $\mathrm{Ca}^{2+}$ uniporter is critical for storeoperated $\mathrm{Ca}^{2+}$ entry-dependent breast cancer cell migration. Biochem Biophys Res Commun 458: 186-193, 2015.

5. Chen L, Sun Q, Zhou D, Song W, Yang Q, Ju B, Zhang L, Xie H, Zhou L, Hu Z, et al: HINT2 triggers mitochondrial $\mathrm{Ca}^{2+}$ influx by regulating the mitochondrial $\mathrm{Ca}^{2+}$ uniporter (MCU) complex and enhances gemcitabine apoptotic effect in pancreatic cancer. Cancer Lett 411: 106-116, 2017.

6. Deak AT, Blass S, Khan MJ, Groschner LN, WaldeckWeiermair M, Hallström S, Graier WF and Malli R: IP3-mediated STIM1 oligomerization requires intact mitochondrial $\mathrm{Ca}^{2+}$ uptake. J Cell Sci 127: 2944-2955, 2014

7. Imbert N, Cognard C, Duport G, Guillou C and Raymond G: Abnormal calcium homeostasis in Duchenne muscular dystrophy myotubes contracting in vitro. Cell Calcium 18: 177-186, 1995.

8. Budd SL and Nicholls DG: A reevaluation of the role of mitochondria in neuronal $\mathrm{Ca}^{2+}$ homeostasis. J Neurochem 66: 403-411, 1996.

9. Hartmann J and Verkhratsky A: Relations between intracellular $\mathrm{Ca}^{2+}$ stores and store-operated $\mathrm{Ca}^{2+}$ entry in primary cultured human glioblastoma cells. J Physiol 513: 411-424, 1998.

10. Hoth M, Button DC and Lewis RS: Mitochondrial control of calcium-channel gating: A mechanism for sustained signaling and transcriptional activation in T lymphocytes. Proc Natl Acad Sci USA 97: 10607-10612, 2000.

11. Jouaville LS, Pinton P, Bastianutto C, Rutter GA and Rizzuto R: Regulation of mitochondrial ATP synthesis by calcium: Evidence for a long-term metabolic priming. Proc Natl Acad Sci USA 96: 13807-13812, 1999.

12. Rizzuto R, Pinton P, Carrington W, Fay FS, Fogarty KE, Lifshitz LM, Tuft RA and Pozzan T: Close contacts with the endoplasmic reticulum as determinants of mitochondrial $\mathrm{Ca}^{2+}$ responses. Science 280: 1763-1766, 1998.

13. Gomez-Suaga P, Paillusson S, Stoica R, Noble W, Hanger DP and Miller CC: The ER-mitochondria tethering complex VAPB-PTPIP51 regulates autophagy. Curr Biol 27: 371-385, 2017.

14. Báthori G, Csordás G, Garcia-Perez C, Davies E and Hajnóczky G: $\mathrm{Ca}^{2+}$-dependent control of the permeability properties of the mitochondrial outer membrane and voltage-dependent anionselective channel (VDAC). J Biol Chem 281: 17347-17358, 2006.

15. Tekmen $\mathrm{M}$ and Gleason E: Multiple $\mathrm{Ca}^{2+}$-dependent mechanisms regulate L-type $\mathrm{Ca}^{2+}$ current in retinal amacrine cells. J Neurophysiol 104: 1849-1866, 2010.

16. Hiester BG, Bourke AM, Sinnen BL, Cook SG, Gibson ES, Smith KR and Kennedy MJ: L-type voltage-gated $\mathrm{Ca}^{2+}$ channels regulate synaptic-activity-triggered recycling endosome fusion in neuronal dendrites. Cell Rep 21: 2134-2146, 2017.

17. Baughman JM, Perocchi F, Girgis HS, Plovanich M, Belcher-Timme CA, Sancak Y, Bao XR, Strittmatter L, Goldberger O, Bogorad RL, et al: Integrative genomics identifies $\mathrm{MCU}$ as an essential component of the mitochondrial calcium uniporter. Nature 476: 341-345, 2011. 
18. Tsai CW, Wu Y, Pao PC, Phillips CB, Williams C, Miller C, Ranaghan M and Tsai MF: Proteolytic control of the mitochondrial calcium uniporter complex. Proc Natl Acad Sci USA 114: 4388-4393, 2017

19. Chen W, Yang J, Chen S, Xiang H, Liu H, Lin D, Zhao S, Peng H, Chen $\mathrm{P}$, Chen AF, et al: Importance of mitochondrial calcium uniporter in high glucose-induced endothelial cell dysfunction. Diab Vasc Dis Res 14: 494-501, 2017.

20. Luongo TS, Lambert JP, Gross P, Nwokedi M, Lombardi AA, Shanmughapriya S, Carpenter AC, Kolmetzky D, Gao E, van Berlo $\mathrm{JH}$, et al: The mitochondrial $\mathrm{Na}^{+} / \mathrm{Ca}^{2+}$ exchanger is essential for $\mathrm{Ca}^{2+}$ homeostasis and viability. Nature 545: 93-97, 2017.

21. Roy S, Dey K, Hershfinkel M, Ohana E and Sekler I: Identification of residues that control $\mathrm{Li}^{+}$versus $\mathrm{Na}^{+}$dependent $\mathrm{Ca}^{2+}$ exchange at the transport site of the mitochondrial NCLX. Biochim Biophys Acta Mol Cell Res 1864: 997-1008, 2017.

22. Austin S, Tavakoli M, Pfeiffer C, Seifert J, Mattarei A, De Stefani D, Zoratti M and Nowikovsky K: LETM1-mediated $\mathrm{K}^{+}$and $\mathrm{Na}^{+}$homeostasis regulates mitochondrial $\mathrm{Ca}^{2+}$ efflux. Front Physiol 8: 839, 2017.

23. Melchionda M, Pittman JK, Mayor R and Patel S: $\mathrm{Ca}^{2+} / \mathrm{H}^{+}$ exchange by acidic organelles regulates cell migration in vivo. J Cell Biol 212: 803-813, 2016.

24. Shao J, Fu Z, Ji Y, Guan X, Guo S, Ding Z, Yang X, Cong Y and Shen Y: Leucine zipper-EF-hand containing transmembrane protein 1 (LETM1) forms a Ca ${ }^{2+} / \mathrm{H}^{+}$antiporter. Sci Rep 6: 34174 , 2016.

25. Koshiba T, Detmer SA, Kaiser JT, Chen H, McCaffery JM and Chan DC: Structural basis of mitochondrial tethering by mitofusin complexes. Science 305: 858-862, 2004.

26. Ausman J, Abbade J, Ermini L, Farrell A, Tagliaferro A, Post M and Caniggia I: Ceramide-induced BOK promotes mitochondrial fission in preeclampsia. Cell Death Dis 9: 298, 2018

27. Gutiérrez T, Parra V, Troncoso R, Pennanen C, ContrerasFerrat A, Vasquez-Trincado C, Morales PE, Lopez-Crisosto C, Sotomayor-Flores $\mathrm{C}$, Chiong $\mathrm{M}$, et al: Alteration in mitochondrial $\mathrm{Ca}(2+)$ uptake disrupts insulin signaling in hypertrophic cardiomyocytes. Cell Commun Signal 12: 68, 2014

28. Giorgi C, Bonora M, Sorrentino G, Missiroli S, Poletti F, Suski JM Galindo Ramirez F, Rizzuto R, Di Virgilio F, Zito E, et al: p53 at the endoplasmic reticulum regulates apoptosis in a $\mathrm{Ca}^{2+}$ dependent manner. Proc Natl Acad Sci USA 112: 1779-1784, 2015.

29. Park SJ, Lee SB, Suh Y, Kim SJ, Lee N, Hong JH, Park C, Woo Y, Ishizuka K, Kim JH, et al: DISC1 modulates neuronal stress responses by gate-keeping ER-mitochondria $\mathrm{Ca}^{2+}$ transfer through the MAM. Cell Rep 21: 2748-2759, 2017.

30. Decuypere JP, Welkenhuyzen K, Luyten T, Ponsaerts R, Dewaele M, Molgó J, Agostinis P, Missiaen L, De Smedt H, Parys JB, et al: Ins $(1,4,5) \mathrm{P} 3$ receptor-mediated $\mathrm{Ca}^{2+}$ signaling and autophagy induction are interrelated. Autophagy 7: 1472-1489, 2011.

31. Hur YS, Kim KD, Paek SH and Yoo SH: Evidence for the existence of secretory granule (dense-core vesicle)-based inositol 1,4,5-trisphosphate-dependent $\mathrm{Ca}^{2+}$ signaling system in astrocytes. PLoS One 5: e11973, 2010.

32. Furuichi T, Simon-Chazottes D, Fujino I, Yamada N, Hasegawa M, Miyawaki A, Yoshikawa S, Guénet JL and Mikoshiba K: Widespread expression of inositol 1,4,5-trisphosphate receptor type 1 gene (Insp3r1) in the mouse central nervous system. Receptors Channels 1: 11-24, 1993.

33. Sugiyama T, Yamamoto-Hino M, Miyawaki A, Furuichi T, Mikoshiba K and Hasegawa M: Subtypes of inositol 1,4,5-trisphosphate receptor in human hematopoietic cell lines: Dynamic aspects of their cell-type specific expression. FEBS Lett 349: 191-196, 1994.

34. Cárdenas C, Miller RA, Smith I, Bui T, Molgó J, Müller M, Vais H, Cheung KH, Yang J, Parker I, et al: Essential regulation of cell bioenergetics by constitutive InsP3 receptor $\mathrm{Ca}^{2+}$ transfer to mitochondria. Cell 142: 270-283, 2010.

35. Kennedy ED, Rizzuto R, Theler JM, Pralong WF, Bastianutto C, Pozzan T and Wollheim CB: Glucose-stimulated insulin secretion correlates with changes in mitochondrial and cytosolic $\mathrm{Ca}^{2+}$ in aequorin-expressing INS-1 cells. J Clin Invest 98: 2524-2538, 1996.

36. Kennedy HJ, Pouli AE, Ainscow EK, Jouaville LS, Rizzuto R and Rutter GA: Glucose generates sub-plasma membrane ATP microdomains in single islet beta-cells. Potential role for strategically located mitochondria. J Biol Chem 274: 13281-13291, 1999.
37. Rutter GA, Burnett P, Rizzuto R, Brini M, Murgia M, Pozzan T, Tavaré JM and Denton RM: Subcellular imaging of intramitochondrial $\mathrm{Ca}^{2+}$ with recombinant targeted aequorin: Significance for the regulation of pyruvate dehydrogenase activity. Proc Natl Acad Sci USA 93: 5489-5494, 1996.

38. Territo PR, Mootha VK, French SA and Balaban RS: $\mathrm{Ca}(2+)$ activation of heart mitochondrial oxidative phosphorylation: Role of the $\mathrm{F}(0) / \mathrm{F}(1)$-ATPase. Am J Physiol Cell Physiol 278: C423-C435, 2000

39. Gizak A, Pirog M and Rakus D: Muscle FBPase binds to cardiomyocyte mitochondria under glycogen synthase kinase-3 inhibition or elevation of cellular $\mathrm{Ca}^{2+}$ level. FEBS Lett 586: $13-19,2012$

40. Wiśniewski J, Piróg M, Hołubowicz R, Dobryszycki P, McCubrey JA, Rakus D and Gizak A: Dimeric and tetrameric forms of muscle fructose-1,6-bisphosphatase play different roles in the cell. Oncotarget 8: 115420-115433, 2017.

41. Han XJ, Lu YF, Li SA, Kaitsuka T, Sato Y, Tomizawa K, Nairn AC, Takei K, Matsui $\mathrm{H}$ and Matsushita M: CaM kinase I alpha-induced phosphorylation of Drp1 regulates mitochondrial morphology. J Cell Biol 182: 573-585, 2008.

42. Ji WK, Hatch AL, Merrill RA, Strack S and Higgs HN: Actin filaments target the oligomeric maturation of the dynamin GTPase Drp1 to mitochondrial fission sites. eLife 4: e11553, 2015.

43. Xu S, Pi H, Chen Y, Zhang N, Guo P, Lu Y, He M, Xie J, Zhong M, Zhang Y, et al: Cadmium induced Drp1-dependent mitochondrial fragmentation by disturbing calcium homeostasis in its hepatotoxicity. Cell Death Dis 4: e540, 2013.

44. Pennanen C, Parra V, López-Crisosto C, Morales PE, Del Campo A, Gutierrez T, Rivera-Mejías P, Kuzmicic J, Chiong M, Zorzano A, et al: Mitochondrial fission is required for cardiomyocyte hypertrophy mediated by a $\mathrm{Ca}^{2+}$-calcineurin signaling pathway. J Cell Sci 127: 2659-2671, 2014

45. Ohshima Y, Takata N, Suzuki-Karasaki M, Yoshida Y, Tokuhashi Y and Suzuki-Karasaki Y: Disrupting mitochondrial $\mathrm{Ca}^{2+}$ homeostasis causes tumor-selective TRAIL sensitization through mitochondrial network abnormalities. Int J Oncol 51: 1146-1158, 2017

46. Wang $\mathrm{X}$ and Schwarz TL: The mechanism of $\mathrm{Ca}^{2+}$-dependent regulation of kinesin-mediated mitochondrial motility. Cell 136 163-174, 2009.

47. Kremneva E, Kislin M, Kang X and Khiroug L: Motility of astrocytic mitochondria is arrested by $\mathrm{Ca}^{2+}$-dependent interaction between mitochondria and actin filaments. Cell Calcium 53 85-93, 2013.

48. Gandhi S, Wood-Kaczmar A, Yao Z, Plun-Favreau H, Deas E, Klupsch K, Downward J, Latchman DS, Tabrizi SJ, Wood NW, et al: PINK1-associated Parkinson's disease is caused by neuronal vulnerability to calcium-induced cell death. Mol Cell 33: 627-638, 2009.

49. Dagda RK, Cherra SJ III, Kulich SM, Tandon A, Park D and Chu CT: Loss of PINK1 function promotes mitophagy through effects on oxidative stress and mitochondrial fission. J Biol Chem 284: 13843-13855, 2009.

50. Gelmetti V, De Rosa P, Torosantucci L, Marini ES, Romagnoli A, Di Rienzo M, Arena G, Vignone D, Fimia GM and Valente EM: PINK1 and BECN1 relocalize at mitochondria-associated membranes during mitophagy and promote ER-mitochondria tethering and autophagosome formation. Autophagy 13: 654-669, 2017.

51. Evans JH and Falke JJ: $\mathrm{Ca}^{2+}$ influx is an essential component of the positive-feedback loop that maintains leading-edge structure and activity in macrophages. Proc Natl Acad Sci USA 104: 16176-16181, 2007.

52. Gottlieb TM, Leal JF, Seger R, Taya Y and Oren M: Cross-talk between Akt, p53 and Mdm2: Possible implications for the regulation of apoptosis. Oncogene 21: 1299-1303, 2002

53. Missiroli S, Danese A, Iannitti T, Patergnani S, Perrone M, Previati M, Giorgi C and Pinton P: Endoplasmic reticulummitochondria $\mathrm{Ca}^{2+}$ crosstalk in the control of the tumor cell fate. Biochim Biophys Acta Mol Cell Res 1864: 858-864, 2017.

54. Ren T, Zhang H, Wang J, Zhu J, Jin M, Wu Y, Guo X, Ji L, Huang Q, Zhang $\mathrm{H}$, et al: MCU-dependent mitochondrial $\mathrm{Ca}^{2+}$ inhibits NAD ${ }^{+} / \mathrm{SIRT} 3 / \mathrm{SOD} 2$ pathway to promote ROS production and metastasis of HCC cells. Oncogene 36: 5897-5909, 2017.

55. Betz C, Stracka D, Prescianotto-Baschong C, Frieden M, Demaurex N and Hall MN: Feature Article: mTOR complex 2-Akt signaling at mitochondria-associated endoplasmic reticulum membranes (MAM) regulates mitochondrial physiology. Proc Natl Acad Sci USA 110: 12526-12534, 2013. 
56. Rimessi A, Marchi S, Patergnani S and Pinton P: H-Ras-driven tumoral maintenance is sustained through caveolin-1-dependent alterations in calcium signaling. Oncogene 33: 2329-2340, 2014.

57. Matsumoto T, Uchiumi T, Monji K, Yagi M, Setoyama D, Amamoto R, Matsushima Y, Shiota M, Eto M and Kang D: Doxycycline induces apoptosis via ER stress selectively to cells with a cancer stem cell-like properties: Importance of stem cell plasticity. Oncogenesis 6: 397, 2017.

58. Seervi M, Sobhan PK, Joseph J, Ann Mathew K and Santhoshkumar TR: ERO1 $\alpha$-dependent endoplasmic reticulummitochondrial calcium flux contributes to ER stress and mitochondrial permeabilization by procaspase-activating compound-1 (PAC-1). Cell Death Dis 4: e968, 2013.

59. Wu LF, Guo YT, Zhang QH, Xiang MQ, Deng W, Ye YQ, $\mathrm{Pu} \mathrm{ZJ}$, Feng JL and Huang GY: Enhanced antitumor effects of adenoviral-mediated siRNA against GRP78 gene on adenosineinduced apoptosis in human hepatoma HepG2 cells. Int J Mol Sci 15: 525-544, 2014

60. Shibao K, Fiedler MJ, Nagata J, Minagawa N, Hirata K, Nakayama Y, Iwakiri Y, Nathanson $\mathrm{MH}$ and Yamaguchi K: The type III inositol 1,4,5-trisphosphate receptor is associated with aggressiveness of colorectal carcinoma. Cell Calcium 48: 315-323, 2010

61. Sakakura C, Hagiwara A, Fukuda K, Shimomura K, Takagi T, Kin S, Nakase Y, Fujiyama J, Mikoshiba K, Okazaki Y, et al: Possible involvement of inositol 1,4,5-trisphosphate receptor type 3 (IP3R3) in the peritoneal dissemination of gastric cancers. Anticancer Res 23: 3691-3697, 2003.

62. Monaco G, Decrock E, Arbel N, van Vliet AR, La Rovere RM, De Smedt H, Parys JB, Agostinis P, Leybaert L, ShoshanBarmatz V, et al: The BH4 domain of anti-apoptotic Bcl-XL, but not that of the related $\mathrm{Bcl}-2$, limits the voltage-dependent anion channel 1 (VDAC1)-mediated transfer of pro-apoptotic $\mathrm{Ca}^{2+}$ signals to mitochondria. J Biol Chem 290: 9150-9161, 2015

63. Xu ZH, Liu CH, Hang JB, Gao BL and Hu JA: Rituximab effectively reverses tyrosine kinase inhibitors (TKIs) resistance through inhibiting the accumulation of rictor on mitochondriaassociated ER-membrane (MAM). Cancer Biomark 20: 581-588, 2017.

64. Rehman J, Zhang HJ, Toth PT, Zhang Y, Marsboom G, Hong Z, Salgia R, Husain AN, Wietholt C and Archer SL: Inhibition of mitochondrial fission prevents cell cycle progression in lung cancer. FASEB J 26: 2175-2186, 2012.

65. Zhao J, Zhang J, Yu M, Xie Y, Huang Y, Wolff DW, Abel PW and Tu Y: Mitochondrial dynamics regulates migration and invasion of breast cancer cells. Oncogene 32: 4814-4824, 2013.

66. Ferreira-da-Silva A, Valacca C, Rios E, Pópulo H, Soares P, Sobrinho-Simões M, Scorrano L, Máximo V and Campello S: Mitochondrial dynamics protein Drp1 is overexpressed in oncocytic thyroid tumors and regulates cancer cell migration. PLoS One 10: e0122308, 2015.

67. Pan L, Zhou L, Yin W, Bai J and Liu R: miR-125a induces apoptosis, metabolism disorder and migrationimpairment in pancreatic cancer cells by targeting Mfn2-related mitochondrial fission. Int J Oncol 53: 124-136, 2018.

68. Huang Q, Cao H, Zhan L, Sun X, Wang G, Li J, Guo X, Ren T, Wang Z, Lyu Y, et al: Mitochondrial fission forms a positive feedback loop with cytosolic calcium signaling pathway to promote autophagy in hepatocellular carcinoma cells. Cancer Lett 403: 108-118, 2017

69. Wang W, Xie Q, Zhou X, Yao J, Zhu X, Huang P, Zhang L, Wei J, $\mathrm{Xie} \mathrm{H}$, Zhou L, et al: Mitofusin-2 triggers mitochondria $\mathrm{Ca}^{2+}$ influx from the endoplasmic reticulum to induce apoptosis in hepatocellular carcinoma cells. Cancer Lett 358: 47-58, 2015

70. Zhou X, Zhang L, Zheng B, Yan Y, Zhang Y, Xie H, Zhou L, Zheng S and Wang W: MicroRNA-761 is upregulated in hepatocellular carcinoma and regulates tumorigenesis by targeting Mitofusin-2. Cancer Sci 107: 424-432, 2016.

71. Rodrigues MA, Gomes DA, Leite MF, Grant W, Zhang L, Lam W, Cheng YC, Bennett AM and Nathanson MH: Nucleoplasmic calcium is required for cell proliferation. J Biol Chem 282: 17061-17068, 2007.

72. Hu J, Qin K, Zhang Y, Gong J, Li N, Lv D, Xiang R and Tan X: Downregulation of transcription factor Oct4 induces an epithelial-to-mesenchymal transition via enhancement of $\mathrm{Ca}^{2+}$ influx in breast cancer cells. Biochem Biophys Res Commun 411: 786-791, 2011.

73. Cho KB, Cho MK, Lee WY and Kang KW: Overexpression of c-myc induces epithelial mesenchymal transition in mammary epithelial cells. Cancer Lett 293: 230-239, 2010.
74. Yang S, Zhang JJ and Huang XY: Orai1 and STIM1 are critical for breast tumor cell migration and metastasis. Cancer Cell 15: 124-134, 2009.

75. Prakriya M, Feske S, Gwack Y, Srikanth S, Rao A and Hogan PG: Orail is an essential pore subunit of the CRAC channel. Nature 443: 230-233, 2006

76. Stewart TA, Azimi I, Thompson EW, Roberts-Thomson SJ and Monteith GR: A role for calcium in the regulation of ATP-binding cassette, sub-family $\mathrm{C}$, member 3 (ABCC3) gene expression in a model of epidermal growth factor-mediated breast cancer epithelial-mesenchymal transition. Biochem Biophys Res Commun 458: 509-514, 2015.

77. Davis FM, Peters AA, Grice DM, Cabot PJ, Parat MO, Roberts-Thomson SJ and Monteith GR: Non-stimulated, agoniststimulated and store-operated $\mathrm{Ca}^{2+}$ influx in MDA-MB-468 breast cancer cells and the effect of EGF-induced EMT on calcium entry. PLoS One 7: e36923, 2012.

78. Tajeddine $\mathrm{N}$ and Gailly P: TRPC1 protein channel is major regulator of epidermal growth factor receptor signaling. J Biol Chem 287: 16146-16157, 2012.

79. Hou T, Jian C, Xu J, Huang AY, Xi J, Hu K, Wei L, Cheng H and Wang X: Identification of EFHD1 as a novel $\mathrm{Ca}(2+)$ sensor for mitoflash activation. Cell Calcium 59: 262-270, 2016.

80. Li W, Sun T, Liu B, Wu D, Qi W, Wang X, Ma Q and Cheng H: Regulation of mitoflash biogenesis and signaling by mitochondrial dynamics. Sci Rep 6: 32933, 2016.

81. Rosselin M, Santo-Domingo J, Bermont F, Giacomello $\mathrm{M}$ and Demaurex N: L-OPA1 regulates mitoflash biogenesis independently from membrane fusion. EMBO Rep 18: 451-463, 2017

82. Ying Z, Chen K, Zheng L, Wu Y, Li L, Wang R, Long Q, Yang L, Guo J, Yao D, et al: Transient activation of mitoflashes modulates nanog at the early phase of somatic cell reprogramming. Cell Metab 23: 220-226, 2016

83. Burch TC, Rhim JS and Nyalwidhe JO: Mitochondria biogenesis and bioenergetics gene profiles in isogenic prostate cells with different malignant phenotypes. BioMed Res Int 2016: 1785201, 2016.

84. Li Y, Huang S, Li Y, Zhang W, He K, Zhao M, Lin H, Li D, Zhang H, Zheng Z, et al: Decreased expression of LncRNA SLC25A25-AS1 promotes proliferation, chemoresistance, and EMT in colorectal cancer cells. Tumour Biol 37: 14205-14215, 2016.

85. Tsai FC and Meyer T: $\mathrm{Ca}^{2+}$ pulses control local cycles of lamellipodia retraction and adhesion along the front of migrating cells. Curr Biol 22: 837-842, 2012.

86. de Lucas B, Bernal A, Pérez LM, San Martín N and Gálvez BG: Membrane blebbing is required for mesenchymal precursor migration. PLoS One 11: e0150004, 2016.

87. Sroka J, Krecioch I, Zimolag E, Lasota S, Rak M, Kedracka-Krok S, Borowicz P, Gajek M and Madeja Z: Lamellipodia and membrane blebs drive efficient electrotactic migration of rat walker carcinosarcoma cells WC 256. PLoS One 11: e0149133, 2016

88. Gambade A, Zreika S, Guéguinou M, Chourpa I, Fromont G, Bouchet AM, Burlaud-Gaillard J, Potier-Cartereau M, Roger S, Aucagne V, et al: Activation of TRPV2 and BKCa channels by the LL-37 enantiomers stimulates calcium entry and migration of cancer cells. Oncotarget 7: 23785-23800, 2016.

89. Yu C, Wang Y, Peng J, Shen Q, Chen M, Tang W, Li X, Cai C, Wang B, Cai S, et al: Mitochondrial calcium uniporter as a targe of microRNA-340 and promoter of metastasis via enhancing the Warburg effect. Oncotarget 8: 83831-83844, 2017.

90. Park JH, Kim HK, Jung H, Kim KH, Kang MS, Hong JH, Yu BC, Park S, Seo SK, Choi IW, et al: NecroX-5 prevents breast cancer metastasis by AKT inhibition via reducing intracellular calcium levels. Int J Oncol 50: 185-192, 2017.

91. Monet M, Lehen'kyi V, Gackiere F, Firlej V, Vandenberghe M, Roudbaraki M, Gkika D, Pourtier A, Bidaux G, Slomianny C, et al: Role of cationic channel TRPV2 in promoting prostate cancer migration and progression to androgen resistance. Cancer Res 70: 1225-1235, 2010.

92. Panahi G, Pasalar P, Zare M, Rizzuto R and Meshkani R: MCU-knockdown attenuates high glucose-induced inflammation through regulating MAPKs/NF- $\kappa$ B pathways and ROS production in HepG2 cells. PLoS One 13: e0196580, 2018.

93. Corazao-Rozas P, Guerreschi P, André F, Gabert PE, Lancel S, Dekiouk S, Fontaine D, Tardivel M, Savina A, Quesnel B, et al: Mitochondrial oxidative phosphorylation controls cancer cell's life and death decisions upon exposure to MAPK inhibitors. Oncotarget 7: 39473-39485,2016. 
94. Patergnani S, Giorgi C, Maniero S, Missiroli S, Maniscalco P, Bononi I, Martini F, Cavallesco G, Tognon M and Pinton P: The endoplasmic reticulum mitochondrial calcium cross talk is downregulated in malignant pleural mesothelioma cells and plays a critical role in apoptosis inhibition. Oncotarget 6: 23427-23444, 2015.

95. Ren T, Wang J, Zhang H, Yuan P, Zhu J, Wu Y, Huang Q, Guo X, Zhang J, Ji L, et al: MCUR1-Mediated Mitochondrial Calcium Signaling Facilitates Cell Survival of Hepatocellular Carcinoma via Reactive Oxygen Species-Dependent P53 Degradation. Antioxid Redox Signal 28: 1120-1136, 2018.

96. Lehen'kyi V, Flourakis M, Skryma R and Prevarskaya N: TRPV6 channel controls prostate cancer cell proliferation via $\mathrm{Ca}(2+)$ /NFAT-dependent pathways. Oncogene 26: 7380-7385, 2007.

97.Høyer-Hansen M, Bastholm L, Szyniarowski P, Campanella M, Szabadkai G, Farkas T, Bianchi K, Fehrenbacher N, Elling F, Rizzuto R, et al: Control of macroautophagy by calcium, calmodulin-dependent kinase kinase-beta, and Bcl-2. Mol Cell 25: 193-205, 2007.

98.Luyten T, Welkenhuyzen K, Roest G, Kania E, Wang L, Bittremieux M, Yule DI, Parys JB and Bultynck G: Resveratrolinduced autophagy is dependent on IP3Rs and on cytosolic $\mathrm{Ca}^{2}$. Biochim Biophys Acta Mol Cell Res 1864: 947-956, 2017.

99. Cárdenas C, Müller M, McNeal A, Lovy A, Jaňa F, Bustos G, Urra F, Smith N, Molgó J, Diehl JA, et al: Selective vulnerability of cancer cells by inhibition of $\mathrm{Ca}(2+)$ transfer from endoplasmic reticulum to mitochondria. Cell Rep 14: 2313-2324, 2016.

100.Martin KR, Celano SL, Solitro AR, Gunaydin H, Scott M, O'Hagan RC, Shumway SD, Fuller P and MacKeigan JP: A potent and selective ULK1 inhibitor suppresses autophagy and sensitizes cancer cells to nutrient stress. iScience 8: 74-84, 2018.

101.Raturi A, Gutiérrez T, Ortiz-Sandoval C, Ruangkittisakul A, Herrera-Cruz MS, Rockley JP, Gesson K, Ourdev D, Lou PH, Lucchinetti E, et al: TMX1 determines cancer cell metabolism as a thiol-based modulator of ER-mitochondria $\mathrm{Ca}^{2+}$ flux. J Cell Biol 214: 433-444, 2016.

102. Nutt LK, Pataer A, Pahler J, Fang B, Roth J, McConkey DJ and Swisher SG: Bax and Bak promote apoptosis by modulating endoplasmic reticular and mitochondrial $\mathrm{Ca}^{2+}$ stores. J Biol Chem 277: 9219-9225, 2002.
103. Scorrano L, Oakes SA, Opferman JT, Cheng EH, Sorcinelli MD, Pozzan T and Korsmeyer SJ: BAX and BAK regulation of endoplasmic reticulum $\mathrm{Ca}^{2+}$ : A control point for apoptosis. Science 300: 135-139, 2003

104. Echeverry N, Bachmann D, Ke F, Strasser A, Simon HU and Kaufmann T: Intracellular localization of the BCL-2 family member BOK and functional implications. Cell Death Differ 20: 785-799, 2013.

105. Giorgi C, Ito K, Lin HK, Santangelo C, Wieckowski MR, Lebiedzinska M, Bononi A, Bonora M, Duszynski J, Bernardi R, et al: PML regulates apoptosis at endoplasmic reticulum by modulating calcium release. Science 330: 1247 1251,2010

106. Bononi A, Bonora M, Marchi S, Missiroli S, Poletti F, Giorgi C, Pandolfi PP and Pinton P: Identification of PTEN at the ER and MAMs and its regulation of $\mathrm{Ca}(2+)$ signaling and apoptosis in a protein phosphatase-dependent manner. Cell Death Differ 20: $1631-1643,2013$

107. Verfaillie T, Rubio N, Garg AD, Bultynck G, Rizzuto R, Decuypere JP, Piette J, Linehan C, Gupta S, Samali A, et al: PERK is required at the ER-mitochondrial contact sites to convey apoptosis after ROS-based ER stress. Cell Death Differ 19: 1880-1891, 2012.

108. Li C, Liu Q, Li N, Chen W, Wang L, Wang Y, Yu Y and Cao X: EAPF/Phafin-2, a novel endoplasmic reticulum-associated protein, facilitates TNF-alpha-triggered cellular apoptosis through endoplasmic reticulum-mitochondrial apoptotic pathway. J Mol Med (Berl) 86: 471-484, 2008.

109. Iwasawa R, Mahul-Mellier AL, Datler C, Pazarentzos E and Grimm S: Fis1 and Bap31 bridge the mitochondria-ER interface to establish a platform for apoptosis induction. EMBO J 30: $556-568,2011$.

110. Namba T, Tian F, Chu K, Hwang SY, Yoon KW, Byun S, Hiraki M, Mandinova A and Lee SW: CDIP1-BAP31 complex transduces apoptotic signals from endoplasmic reticulum to mitochondria under endoplasmic reticulum stress. Cell Rep 5: 331-339, 2013. 